\title{
Addictive agents and intracranial stimulation (ICS): Pressing for ICS before and after self-administration of sweetened morphine solutions
}

\author{
MARCIA L. COLLAER, DEBRA J. MAGNUSON, and LARRY D. REID \\ Bradley University, Peoria, Illinois 61606
}

\begin{abstract}
Rats, fixed with chronically indwelling electrodes for intracranial stimulation (ICS) of the lateral hypothalamic area, pressed a lever for the ICS. They were then given 15 days of opportunity to consume a sweetened morphine solution. They increased their intake of the solution to a mean of $61 \mathrm{mg} / \mathrm{kg} /$ day of morphine by the 15th day. During the initial days of 37 days of abstinence, they showed pronounced withdrawal symptoms. Subsequently, they were given another opportunity to consume and they relapsed into taking large quantities of morphine. After another 10 days of abstinence, rats were tested for pressing for ICS before and after $3 \mathrm{~h}$ of opportunity to consume sweetened morphine solution (mean morphine consumption = $28 \mathrm{mg} / \mathrm{kg} / \mathrm{session}$ ). The rats pressed reliably more after taking the morphine solution than before taking it and more than on days when they only consumed the sweetened solution without morphine. Consequently, it was concluded that pressing for ICS was accelerated after selfadministration of morphine by previously addicted rats.
\end{abstract}

Morphine can, under certain circumstances, accelerate pressing for lateral hypothalamic intracranial stimulation (ICS) (Adams, Lorens, \& Mitchell, 1972). Furthermore, from the extant research (e.g., Adams et al., 1972; Bush, Bush, Miller, \& Reid, 1976; Liebman \& Segal, 1976), the circumstances leading to accelerated pressing can be roughly described. Changes in pressing for hypothalamic ICS are a function of a complex interaction of dose, time of testing after injections, and days of injections. Press rates are depressed with large doses when the interval between injections and testing is brief, but as the interval between injections and testing increases, press rates are apt to be accelerated. Press rates are also accelerated with small doses. With days of dosing, the initial depressive effects wane and the period of acceleration moves closer and closer to the time of dosing. When press rates are low, morphine has a more marked effect than when press rates are high, i.e., low press rates are, in general, more labile with respect to drug effects (Dews, 1971). Also, there are differences in reactivity depending on the site of ICS. Despite the fact that the acceleration in pressing for ICS with mor-

This research was supported by Grant DA01049 from the National Institute of Drug Abuse, DHEW. Debra Magnuson is now at the University of Illinois at the Medical Center, Department of Anatomy, Chicago, Illinois. Larry Reid is now at the Department of Psychology, Rensselaer Polytechnic Institute, Troy, New York 12181. Correspondence should be addressed to L. Reid. phine occurs only under certain circumstances, the acceleration is of interest.

It has been suggested that morphine's acceleration of pressing for positive ICS, or the concommitant lowering of threshold for positive intracranial reinforcement, reflects the positively reinforcing or euphorigenic properties of morphine (Esposito \& Kornetsky, 1977; Farber \& Reid, 1976; Rossi \& Reid, 1976). Since the acceleration, once seen, does not wane with repeated dosing, at least up to 40 days of dosing with $20 \mathrm{mg} / \mathrm{kg} /$ day (Zipnick, Kelley, \& Reid, Note 1), it could reflect a factor of considerable importance in the maintenance of the behavior of morphine assimilation. If, however, the morphine's acceleration of pressing for ICS is related to selfadministration of morphine, then such acceleration must be shown to occur after self-administration. Furthermore, if the acceleration of pressing reflects processes that might occur in addicted individuals, it must occur in individuals that have taken substantial quantities of morphine. Consequently, in this study, press rates for hypothalamic ICS were measured before and after self-administration of morphine among rats having a history of being avid consumers of sweetened morphine solutions.

\section{METHOD}

\footnotetext{
Subjects

The subjects were adult, male, albino rats. Each rat was fixed, in standard ways, with a chronically indwelling bipolar electrode. The electrodes (Plastic Products, ms 303) were two stainless steel wires insulated except at the cross section of their stimulating
} 
tips. The distance between the two poles of the electrode was only the width of the insulation.

Each of the subjects had participated in an earlier study of pressing for ICS. Consequently, all rats had experienced from 45 to 63 daily sessions with ICS, each of about $4 \mathrm{~min}$, prior to the beginning of this study. Five of the last of these daily sessions were under the influence of $10-\mathrm{mg} / \mathrm{kg}$ subcutaneous injections of morphine sulfate. Compared to mean pressing on the day before morphine injections, the subjects included in this experiment increased their pressing for ICS on the 5th day of morphine administration by about $10 \%$. One day after these initial tests with ICS, the procedures of this experiment began.

From the time of their surgery, the rats lived in individual cages with food and water constantly available. Their weights ranged from 370 to $555 \mathrm{~g}$ at the outset of this experiment.

\begin{abstract}
Apparatus
Subjects were tested in a clear Lucite box $(24 \times 30 \times 35 \mathrm{~cm})$ fitted with a lever $(2.7 \times 2.0 \mathrm{~cm}, 7.0 \mathrm{~cm}$ from the floor $)$. Depression of the lever resulted in an ICS of $0.25 \mathrm{sec}, 60-\mathrm{Hz}$ sine waves, of varying intensities but always less than $50 \mu \mathrm{A}$ (root mean square). The rats' movements were unhampered by the light, flexible electrode leads. Number of presses (ICSs) during testing were recorded automatically.

To measure consumption of fluids, bottles with ball-point sipping tubes were weighed. Taking into account the density of the fluid, all measures were converted to milliliters. Graduated bottles, marked in milliliters, were used, however, to measure consumption periodically on the last day of morphine availability.
\end{abstract}

\section{Procedure}

Prior to this study, the subjects were fixed with electrodes, allowed at least 5 days to recover from surgery, screened for pressing for ICS, and allowed to press daily with a selected intensity of ICS for 45 to 63 days. This study has three phases: (1) pretesting phase, involving morphine consumption; (2) a 2-day period during which rats reestablished steady pressing for ICS; and (3) a 14-day testing phase.

Rats were given an opportunity to consume sweetened morphine solutions marking the start of the procedures of this study. For $23.75 \mathrm{~h} /$ day, they were presented a solution of $18 \%$ sucrose in tap water with $0.5 \mathrm{mg} / \mathrm{ml}$ of morphine sulfate ( $18 \mathrm{~g}$ of table sugar to $100 \mathrm{ml}$ of solution). As stated, the rats always had food and water available. The morphine solution was available for 15 days.

After 15 days of opportunity to consume, the rats were given no opportunity to take morphine for 37 days. During the initial period of abstinence, the rats were observed periodically and weighed. After this abstinence, they were given another opportunity to consume the morphine solution for 3 days. After these 3 days, there were another 10 days of abstinence. On the 4 th day of these latter 10 days of abstinence, tests of pressing for ICS were reinstated.

On the basis of high consumption of the sweetened morphine solution, 12 rats were chosen from a subject pool of 36 , and these 12 are the subjects of the remainder of these procedures. The rats were tested twice daily for pressing rates for a fixed intensity of ICS. Testing consisted of a 5-min session in which the subjects were allowed to press for ICS. The intensities were, in general, those of their tests prior to opportunity to consume morphine. Intensities ranged from 14 to $40 \mu \mathrm{A}$ and sustained moderate pressing rates without side effects of seizures, inordinate forced movements, or prolonged pauses in pressing. Each 5-min measurement of pressing rates was preceded by at least 10 selfdelivered ICS to ensure that measurement of rats' pressing was not confounded with hesitancy to begin pressing.

There was one test for pressing rates that began at 11:00 a.m. and another that began at 3:00 p.m. For 2 days, while rats were becoming reacquainted with pressing, no special procedures intervened between tests. Across the next 5 days, a sucrose solution $(5 \%$ sucrose, $\mathrm{w} / \mathrm{v})$ was presented for $3 \mathrm{~h}$ to the rats in their home cages. The presentation of the solution began $0.5 \mathrm{~h}$ after the first test with ICS and ended $0.5 \mathrm{~h}$ before the second test with ICS. Across the next 6 days of tests with ICS, the sweetened morphine solution was presented for $3 \mathrm{~h}$ in the same way as the previously presented sucrose solution. The sweetened morphine solution was the same as described earlier $(18 \%$ sucrose, $0.5 \mathrm{mg}$. $\mathrm{ml}$ morphine). On the final day of morphine presentation, amounts consumed were recorded at intervals during the $3 \mathrm{~h}$. Across the next 3 days, pressing rates were again recorded before and after presentation of the sucrose-only solution. In summary, rats' pressing rates for ICS were recorded before and after an opportunity to drink a sucrose solution or a sweetened morphine solution. The order of presentation of solution was first sucrose ( 5 days), then sweetened morephine (6 days), and finally sucrose ( 3 days).

The subjects were then sacrificed and their brains were taken using standard procedures. The brains were frozen and cut into slices 90 microns thick. To aid in determination of the site of ICS, enlarged photographs of the sections were made using the sections as photographic negatives.

\section{RESULTS}

As mentioned, the self-stimulating rats of this study were selected from a larger pool on the basis that they consumed large quantities of sweetened morphine solutions. On the 1 st day of consumption, the 12 selected rats drank a mean of $19 \mathrm{ml}$. They escalated their intake of the solution across days until, by the 15th day, they were taking a mean of $51 \mathrm{ml}$ of solution or $61 \mathrm{mg} / \mathrm{kg} /$ day of morphine. When deprived of morphine, the rats showed marked withdrawal symptoms, i.e., they were irritable and showed rapid weight loss. They lost, for example, a mean of $34 \mathrm{~g}$ of body weight from 6 to $72 \mathrm{~h}$ after the last opportunity to consume the solution.

The rats relapsed into taking the sweetened morphine after 37 days of abstinence. They consumed means of 55,72 , and $61 \mathrm{ml}$ of solution, respectively, on the 3 days of opportunity to consume. A comparison of the amount consumed on the 1 st day of relapse to the amount consumed the very 1st day of opportunity to consume yielded a $\mathrm{t}(11)$ $=6.0, \mathrm{p}<.01$. Furthermore, after another 10 days of abstinence, the rats consumed means of $17,21,29$, 28,29 , and $26 \mathrm{ml}$ of the sweetened morphine solution, respectively, across the 6 days when given the opportunity to drink for $3 \mathrm{~h} /$ day during the days of tests with ICS. Since the rats weighed an average of $464 \mathrm{~g}$ on the 6 th day of opportunity to drink for $3 \mathrm{~h} /$ day, and drank a mean of $26 \mathrm{ml}$ of solution, they orally administered a mean of $28 \mathrm{mg} / \mathrm{kg} / 3 \mathrm{~h}$ of morphine. Figure 1 presents the cumulative mean consumption at intervals during the $3 \mathrm{~h}$ on the 6 th day of morphine availability. As can be seen, the rats took about $4 \mathrm{ml}$ during the first $10 \mathrm{~min}$ and, subsequently, a few more milliliters every $1 / 2 \mathrm{~h}$.

Figure 2 summarizes the results of testing with ICS. Mean presses (ICSs) are depicted for each test when a solution was presented between the two tests of a day. When the solution presented between tests 


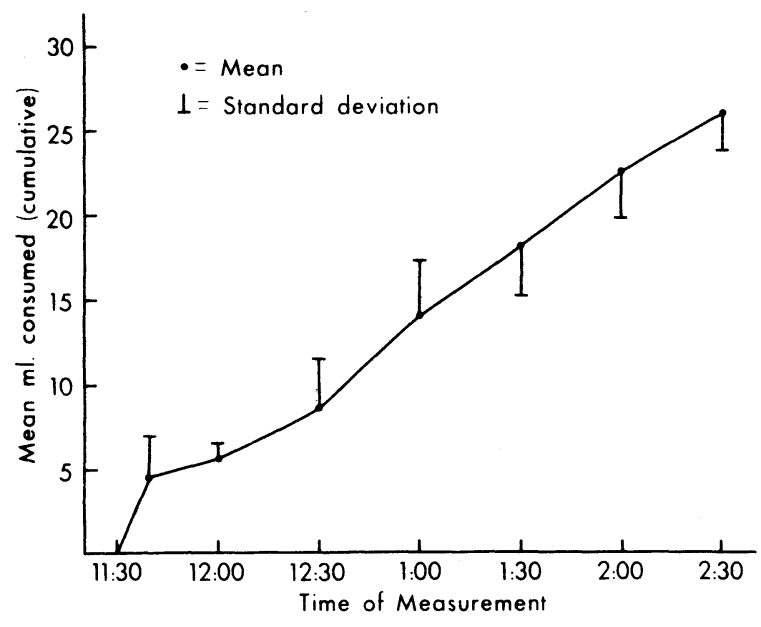

Figure 1. Mean consumption of sweetened morphine solution $(\mathrm{ml})$ is shown at intervals during $3 \mathrm{~h}$ of availability on the sixth presentation.

was only sucrose, $t$ tests indicated that none of the differences between tests of a day approached standards for concluding that any changes in press rates were reliable.

Student $\mathrm{t}$ tests for correlated measures comparing scores from before and after consumption on the 6 days of self-administration of morphine yielded values of $\operatorname{ts}(11)=1.5,3.9,3.8,3.4,2.7$, and 3.1 , respectively, ps $<.05$, with the exception of the one of the 1st day, $\mathrm{p}<.2$. The rats' performances on the second tests of a day (the p.m. tests) were compared. For these comparisons, three scores were derived for every subject, one score for each set of test days. One score was the mean of all p.m. press rates $/ 5 \mathrm{~min}$ prior to morphine availability, i.e., mean presses following the first 5 days of self-administration. The second score was a mean of all press rates $/ 5 \mathrm{~min}$ following morphine-sucrose self-administration. The third score was the mean of the press rates/ 5 min following the final sucrose presentations. Using $t$ tests for correlated measures, these scores were compared: for the scores of premorphine sucrose presentation and scores of morphine presentation, $\mathrm{t}(11)=4.8, \mathrm{p}<.01$; for scores following postmorphine sucrose presentation and scores following morphine presentation, $\mathrm{t}(11)=4.6, \mathrm{p}<.01$. Comparing scores from the two sets of days following sucrose presentation, $\mathrm{t}(11)=.35, \mathrm{p}>.50$. Similar comparisons of mean scores of the first tests of a day yielded no value indicating reliable differences.

In summary, the rats' mean daily pressing for ICS prior to drinking a solution were similar to one another across days. Scores following an opportunity to drink sucrose were similar to one another and were also similar to scores prior to presentation of the solution. The scores, however, following opportunity to consume morphine were reliably higher than the other scores. Also, there was no correlation between amount of morphine taken during the $3 \mathrm{~h}$ and the increment in pressing.

The electrode tips of all subjects were in the medial forebrain bundle, Forel's Fields, or the zona incerta of the lateral hypothalamic area. All sites of ICS were lateral to the mamillo-thalamic tract and medial to the crus cerebri. The anterior-posterior locations extended the length of the ventromedial nucleus of the hypothalamus and somewhat posterior to it.

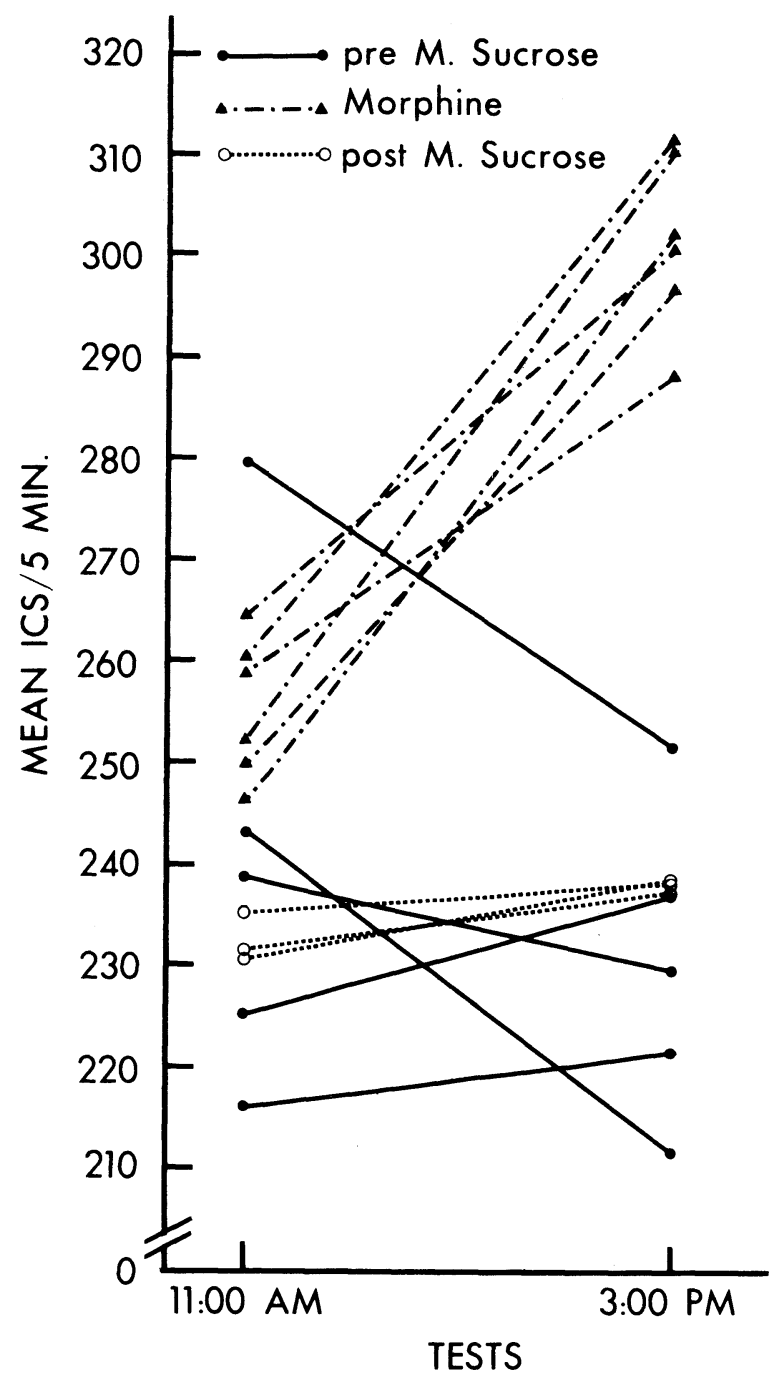

Figure 2. Mean press rates for each of the two daily tests are presented. Tests at 11:00 a.m. were $0.5 \mathrm{~h}$ before the opportunity to consume the solutions. Tests at 3:00 p.m. were $0.5 \mathrm{~h}$ after the opportunity to consume the solutions. Solid lines indicate days of sucrose solutions prior to morphine availability. Dashed lines indicate the days of presentation of sweetened morphine solutions between the two tests of a day. Dotted lines indicate days of sucrose solutions subsequent to presentations with sweetened morphine solutions. 


\section{DISCUSSION}

Prior to tests with ICS, these rats had selfadministered considerable quantities of morphine, had shown withdrawal symptoms, and had relapsed into taking large quantities of morphine after a prolonged abstinence, i.e, these subjects were "addicts." Their self-administration of morphine led to accelerated pressing for a fixed intensity of ICS.

In nonaddicted rats, the increased pressing for ICS following injections of morphine has been interpreted as reflecting the positively reinforcing or euphorigenic actions of morphine. That interpretation is based on what is known, in general, about intracranial reinforcement (Olds, 1969) and specific tests of that interpretation (Farber \& Reid, 1976; Rossi \& Reid, 1976). It is supposed that the morphine either directly or indirectly increases the tonic activity of the tissue of ICS, and thereby leads to greater pressing. Furthermore, such increased activity produces positive affect (positive reinforcement when there is a contingency between specifiable behavior and the affect). Before these conclusions can be further extended to develop a general statement concerning addictions, various components of that line of reasoning must be verified. Two apparently critical events must be demonstrated. They are (a) the acceleration in pressing for morphine has to be shown to follow self-administration of morphine, and (b) acceleration in pressing has to occur among individuals that have assimilated considerable quantities of morphine. Both events were demonstrated in this study. Consequently, this study supports the following hypothesis: Morphine's capacity to sustain the behavior of its assimilation is a product of morphine's actions on some of the tissue of intracranial self-stimulation.

\section{REFERENCE NOTE}

1. Zipnick, J., Kelley, K., \& Reid, L. Addictive agents and intracranial stimulation (ICS): Daily morphine and pressing for combinations of positive and aversive ICS. Paper in preparation.

\section{REFERENCES}

Adams, W. J., Lorens, S. A., \& Mitchell, C. L. Morphine enhances lateral hypothalamic self-stimulation in the rat. Proceedings of the Society of Experimental Biology and Medicine, 1972, 140, 770-771.

Bush, H. D., Bush, M. F., Miller, M. A., \& Reid, L. D. Addictive agents and intracranial stimulation: Daily morphine and lateral hypothalamic self-stimulation. Physiological Psychology, 1976, 4. 79-85.

DEws, P. B. Drug-behavior interactions. In J. A. Harvey (Ed.), Behavioral analysis of drug action. Glenview, Ill: Scott, Foresman, 1971.

Esposito, R., \& Kornetsky, C. Morphine lowering of self-stimulation thresholds: Lack of tolerance with long-term administration. Science, 1977, 195, 189-191.

FARBER, P. D., \& REID, L. D. Addictive agents and intracranial stimulation (ICS): Daily morphine and pressing for combinations of positive and negative ICS. Physiological Psychology, 1976, 4, 262-268.

Liebman, J. M., \& Segal, D. S. Lithium differentially antagonizes self-stimulation facilitated by morphine and $(+)$-amphetamine. Nature, 1976, 260, 161-163.

OLDs, J. The central nervous system and reinforcement of behavior. American Psychologist, 1969, 24, 114-132.

Rossi, N. A., \& REID, L. D. Affective states associated with morphine injections. Physiological Psychology, 1976, 4, 269-274.

(Received for publication April 21, 1977; revision accepted August 24, 1977.) 